\title{
ESCRITOR E IMAGEN DE AUTOR ${ }^{1}$
}

Dominique MAINGUENEAU

Université de la Sorbonne

$\mathrm{P}$

odemos preguntarnos, legítimamente, si el concepto de «imagen de autor» es útil cuando disponemos ya de términos como ethos o postura (Meizoz, 2007). En efecto, me parece que dentro de la tópica sobre la cual reposan los estudios literarios tradicionales, cabe difícilmente la noción de imagen de autor, que no pertenece ni al productor ni al público, sino que aparece como una realidad inestable y confusa, el producto de una interacción entre participantes heterogéneos. Sin embargo, veremos que tal concepto puede revelarse particularmente útil para el análisis del discurso, que está destinado por naturaleza a trabajar en zonas fronterizas. Teniendo en cuenta la extrema complejidad de todo lo que se refiere a la autorialidad, me limitaré aquí al discurso literario, convencido, con todo, de que, mediante algunos ajustes, la mayoría de los funcionamientos que trato son válidos más allá de este ámbito restringido.

\section{Problemas de autor}

Hace mucho tiempo que se estudia «la imagen» de este o aquel escritor, en particular cuando se trata de estudiar la recepción de su obra en un conjunto, periodo o lugar determinados. Lo más habitual es que esta imagen no se analice como una dimensión plena de la enunciación, sino como un fenómeno contingente, exterior a la actividad propiamente literaria. No ocurre lo mismo cuando se lleva a cabo una reflexión sobre la puesta en escena del productor literario -lo que engloba a la vez su trabajo de «presentación de sí» (Goffman) y la representación que se hace de él-. Pero esta problemática es reciente, y sin duda pasarán años antes de que sea explorada de forma sistemática en todos sus aspectos.

El hecho de que este tipo de investigación sea reciente puede explicarse por el peso de la estética dominante, que, tal y como intenté mostrar en diversas ocasiones, y en particular en mi Contre Saint Proust (2006), implica una ruptura fundadora entre el «Texto», necesariamente en mayúscula, y su «contexto»; una ruptura que avala la separación entre «historia literaria» y estudio

\footnotetext{
${ }^{1}$ Este texto apareció originalmente con el título «Écrivain et image d'auteur» en el volumen colectivo Se dire écrivain. Pratiques discursives de la mise en scène de soi, dirigido por Pascal Delormas, Dominique Maingueneau y Inger Østenstad (Lambert-Lucas, 2013). Lo traducimos con autorización del autor, los directores y la editorial. La traducción es de Carole Gouaillier.
} 
inmanente de los textos, ya sea este último temático, estilístico, narratológico... La distinción casi sagrada entre el «yo profundo» del creador y el «yo social» desarrollada por Proust en Contra SainteBeuve relega a un segundo plano lo que no se deja atrapar en esa oposición texto $v s$ contexto, y en particular «la imagen de autor», que en ningún caso puede atañer al «yo profundo», fuente de las obras. Esta ruptura se mantiene, de hecho, en muchos análisis fundados sobre el estudio de las marcas de la enunciación donde uno se aplica obstinadamente a separar «el narrador», figura textual, del «escritor», figura extratextual.

Si hoy podemos interesarnos por la imagen de autor, es porque se está dibujando un nuevo paisaje en los estudios literarios, y mucho más allá. En adelante, enunciar en literatura no es sólo desplegar un mundo ficcional que expresaría una visión singular del mundo, sino también configurar la escena de palabra que es a la vez condición y producto de esta palabra. La dificultad para el analista del discurso que trabaja sobre la imagen de autor consiste entonces a no pasar de un «textualismo» a un «sociologismo» que nos devolvería, bajo un aspecto diferente, a la oposición inmemorial del texto y el contexto. Otras problemáticas estrechamente ligadas como las del «ethos» y de la «postura» (Meizoz, 2007), cada una en su propio orden, rechazan precisamente operar tal disociación. Pero mientras que la problemática del «ethos discursivo» se focaliza en la enunciación propiamente dicha, y que la de la «postura» privilegia las estrategias utilizadas por el productor ${ }^{2}$ para posicionarse en el espacio literario, la problemática de la imagen de autor se centra en la interacción entre el autor y los diferentes públicos que producen discursos sobre el autor: críticos, profesores, gran público...

El primer obstáculo, y puede que el más temible, es que la noción de imagen de autor se sustenta ella misma sobre el término «autor», que ya sabemos que es tan ineludible como difícil de manejar. De hecho, la autorialidad excede toda exterioridad simple del texto y del contexto; opera en una frontera. M. Foucault (1969a) dejó constancia de esa dificultad en un texto célebre, en el cual había desplazado la interrogación esencialista «¿Qué es un autor?» hacia una «función autor».

Para aclarar las cosas, propuse distinguir (Maingueneau, 2009) tres valores distintos, pero en estrecha relación, de esta noción de autor.

El primero, en cierto sentido el más claro, es la de «responsable» [répondant]: la instancia que responde de un texto, que asume la responsabilidad del mismo. Esta acepción no tiene nada específicamente literario ya que «ser el autor de un texto» vale para todo texto. Igual que «el enunciador» de los lingüistas, que no es ni un marcador lingüístico ni un individuo de carne y hueso, la instancia que responde de un texto no es ni el enunciador, ni un individuo de carne y hueso (escritor o persona), sino aquello que los vincula. En teoría literaria, esta entidad intermediaria ha suscitado muchas reflexiones, en particular en torno al paratexto (título, prefacio, nombre de autor...) y a la articulación entre «narrador» y «autor implícito» (Booth, 1961).

\footnotetext{
${ }^{2}$ Hablo de «productor» para evitar un término tan polisémico como «escritor», y por supuesto, como «autor».
} 
Según la segunda acepción, el autor designa un actor de la escena literaria («escritor», «hombre de letra», «literato»...). Se refiere a estatus socialmente identificados con los que están asociadas algunas representaciones estereotipadas históricamente variables.

En la tercera acepción, el autor es el correlato de una obra, lo que propuse llamar un «auctor», identificable en el paisaje mediático e incluso en el Thesaurus («los grandes autores»), en caso de que acceda a la consagración.

Si todo texto tiene un «responsable», sólo un número limitado de individuos acceden a este estatus de «auctor». Una de las singularidades de la producción literaria en relación con otros campos como el periodismo o la política, es que cualquiera que publica deviene virtualmente «auctor» en potencia. En aquellos, se trata de autorialidades que podríamos calificar de «puntuales», en las cuales un productor -individual o colectivo- se ofrece como el responsable (fuese anónimo o pseudónimo) de textos que permanecen en su lugar. Es el caso, por distintos aspectos, del periodista que firma sucesos o reportajes en varios periódicos, del jefe de departamento que envía correos a sus subordinados, del sacerdote que escribe un sermón cada domingo, etc.

Cuando hay constitución de una figura de auctor por el productor mismo, puede ocurrir de dos maneras: la más sencilla consiste en producir textos en géneros que lo cualifican como auctor (una novela, por ejemplo, o un ensayo); la otra, consiste en reunir textos dispersos: es el caso del periodista que reagrupa sus crónicas aparecidas en varios periódicos, del predicador que publica una selección de sus sermones, etc. Este reagrupamiento también puede ser llevado a cabo por un tercero, o a veces por la cooperación del productor y de terceros. La situación, evidentemente, es muy diferente cuando el productor está muerto o es incapaz de intervenir en este reagrupamiento. El caso extremo es el de «auctores» que sólo se convirtieron en tales gracias a la intervención de terceros que, partiendo del postulado de que eran «auctores», les construyeron una verdadera obra, una reunión de textos. En La Arqueología del saber, M. Foucault, dando continuidad a su famoso texto «QQué es un autor?» (Foucault, 1969a) donde se pregunta sobre los presupuestos que hacen la unidad de una obra, escribe al respeto:

De hecho, si se habla tan fácilmente y sin preguntarse más de la «obra» de un autor es porque se la supone definida por cierta función de expresión. Se admite que debe haber en ello un nivel (tan profundo que es necesario imaginarlo) en el cual la obra se revela, en todos sus fragmentos, incluso los más minúsculos y los más inesenciales, como la expresión del pensamiento, o de la experiencia, o de la imaginación, o del inconsciente del autor, o aún de las determinaciones históricas en que estaba inmerso. (Foucault, 1969b: 35) ${ }^{3}$

Algunos auctores acceden incluso al estatus de autoridades: su figura es tan destacada que se publican textos suyos que no estaban destinados a ser publicados: borradores, correspondencia privada, deberes escolares, cuadernos, diarios... Foucault había subrayado este punto:

El nombre «Mallarmé» no se refiere de la misma manera a los temas ingleses, a las traducciones de Edgar Poe, a los poemas o a las respuestas dadas a investigaciones; igualmente, no es la misma la relación que existe entre el nombre de Nietzsche de una parte y de otra las autobiografías de juventud, las

\footnotetext{
${ }^{3}$ Utilizamos la traducción de Aurelio Garzón del Camino (2002: 39). [N. de la T.]
} 
disertaciones escolares, los artículos filológicos, Zaratustra, Ecce homo, las cartas, las últimas tarjetas postales firmadas por «Dionysos» o «Kayser Nietzsche», y los innumerables cuadernillos en los que se cruzan las anotaciones del lavado de ropa con los proyectos de aforismos. (Foucault, 1969b:35) ${ }^{4}$

Algunos ejemplos que menciona Foucault son textos publicados (poemas, en el caso de Mallarmé; Zarathustra, Ecce homo, en el caso de Nietzsche), o textos inacabados (autobiografías de juventud); otros, son textos que contribuyen a la inscripción de su autor en el campo literario, científico o filosófico: traducciones, respuestas a investigaciones, artículos filológicos; otros, el autor no los puso al servicio de la gestión de su imagen de autor: cuadernos, disertaciones, temas ingleses. Para estos auctores asociados a Obras mayores, son las decisiones editoriales fundadas sobre operaciones interpretativas las que harán que tal o cual género por naturaleza excluido por el creador de la gestión de su imagen, contribuya a esta imagen.

Tener en cuenta esta problemática de la imagen de autor me obliga a rectificar ligeramente mis propios conceptos. En Le Discours littéraire (2004), intenté discutir la división elemental del escritor en dos figuras: una que sería creadora de una obra; otra que llevaría una existencia social. Con este fin, desarrollé una distinción entre tres entidades: la «persona» (el individuo fuera de la creación literaria), el «escritor» (el actor en el campo literario), el «inscriptor» (que enuncia el texto). Esas tres entidades no se disponen en secuencia, ya sea en términos de cronología o de estratos, sino que se atraviesan la una a la otra, en una estructura paradójica de nudo borromeo. Así que no hay, primero, «la persona», que sería merecedora de una biografía, después «el escritor» que actuaría en el espacio literario, y finalmente «el inscriptor» que se encargaría de la enunciación: ninguno de los tres es fundamento o pivote.

¿Es suficiente esta distinción entre «persona», «escritor» e «inscriptor»? Sin duda, no. La noción de «inscriptor» tal y como fue introducida presenta el inconveniente de acumular dos papeles (el de enunciador y el de «ministro de la institución literaria») que, ciertamente, están estrechamente ligados pero son heterogéneos. En otros términos, la noción de «inscriptor» mezcla, de hecho, dos niveles: el de «enunciador» y el de «autor-responsable», que, dado que se trata de discurso literario, está en posición de ministro de la institución literaria. Más precisamente, este «responsable» tiene dos grandes funciones: responde de un texto, asume la responsabilidad de éste, y es su disponedor [agenceur] (da un título, divide en capítulos, párrafos, coloca un epígrafe...). La primera función lo orienta hacia la sociedad, la segunda lo orienta hacia el texto propiamente dicho. Estos dos aspectos explican su vínculo privilegiado con el peritexto: un prefacio no está firmado ni por el enunciador ni por el escritor, sino por el «autor».

Así, «el autor-responsable» tiene un papel de intercambiador [échangeur]. En el siglo XVII, a propósito de las epístolas dedicatorias ubicadas al principio de las obras, Charles Sorel escribía, no sin algo de razón, que un prefacio es la «obra maestra» del autor, en la medida en que es una suerte de «portal» de su texto:

\footnotetext{
${ }^{4}$ Pág. 38 de la traducción. La fórmula «temas inglesas» se refiere a la traducción inversa del francés al inglés. [N. de la T.]
} 
Si los Autores tienen alguna doctrina y alguna elocuencia, es aquí dónde la muestran, con el fin de que, desde el principio, se tenga una gran opinión de su Obra, y que sea como un bonito portal que prometa maravillas en el interior del edificio. [...] Presumimos [...] que son las verdaderas obras maestras de los autores, y que se tendría que invertir más tiempo y trabajo en consultar sus grandes Obras, y verlas en su conjunto, para reconocer aquí también el aprecio que se les debe a ellos y a su industria. (Sorel, 1968: 111$112)^{5}$

\section{La imagen de autor}

Se pueden identificar a priori dos zonas de activación, estrechamente ligadas, de una «imagen de autor»:

- La que concierne al texto.

- La que concierne al actor, cuyo comportamiento se apoya y actúa sobre las representaciones colectivas de lo que es la actividad normal de escritor en un lugar y en un momento dados. Retomando los términos utilizados en Le Discours littéraire, podemos decir que este actor se libra a un doble trabajo de «configuración» y de «figuración» en función de la imagen que pretende modelar. La «configuración» está orientada hacia el ajuste de la obra; pasa por varios géneros: manifiestos, debates, escritos sobre otras artes, prefacios a obras de otros escritores, obras sobre otros escritores... Permite reorientar la trayectoria de conjunto en la cual se inscribe cada obra singular: ser escritor es también gestionar la memoria interna de sus textos y de sus actividades anteriores, y reorientarlas en función de un porvenir. A este trabajo de «configuración» se mezcla el trabajo de «figuración» a través del cual el actor, en cierto modo, se pone en escena como escritor: viaja o no, vive retirado en el campo o en el centro de una gran ciudad, sale en televisión o esconde su cara, concede entrevistas a la prensa escrita, etc.

De hecho, la imagen de autor no es sólo el producto de una actividad del autor: se elabora en la confluencia de sus gestos y de sus palabras, por una parte, y las palabras de todos los que, de modos diversos y en función de sus intereses, contribuyen a modelarla.

Muy a menudo, la imagen de autor se elabora sobre todo a posteriori, gracias a terceros, cuando el escritor está muerto. Este tipo de fenómeno no tiene nada de marginal, tratándose de un discurso como el literario que está destinado, por naturaleza, a constituir un Thesaurus. Los productores más valorados, aquellos cuya imagen es más rica, pertenecen a la memoria colectiva, perpetuamente modificada. Así, Rimbaud no devino Rimbaud, no accedió al «mito de Rimbaud», más que tras su muerte ${ }^{6}$. En esta perspectiva, no podemos subestimar la importancia de las decisiones «editoriales». Hablo aquí de los editores en el sentido fuerte, de los que constituyen una obra y no se contentan con reimprimir los textos. Deben apoyarse sobre cierta imagen de autor para constituir una obra, pero ésta, debido a sus decisiones, suscitará una nueva imagen de autor. El fabulista llamado «Esopo» no tiene existencia histórica verificable: funciona como el nombre propio que indexa un corpus de fábulas. Esto no impide que su biografía sea rica, tal y como atestigua la «vida» que colocó La Fontaine al inicio de sus Fábulas. A partir del momento en que una decisión

\footnotetext{
${ }^{5}$ La traducción es nuestra, como siempre que no se indique lo contrario en nota al pie. [N. de la T.]

${ }^{6}$ Dejo aquí de lado la cuestión de las mistificaciones literarias (los autores que no existen) u otras heteronomías (Pessoa).
} 
editorial lo instituye como auctor reconocido y sostenido por una tradición, una imagen de autor puede elaborarse a partir de la biografía que se le asocia: muy a menudo, esta biografía está ella misma destinada a apuntalar esta imagen de autor.

A este respecto, se puede considerar un ejemplo mayor, más cercano a nosotros: el de Pascal, un auctor que, a lo largo de su vida, sólo se dio a ver como autor de opúsculos científicos. Es después de su muerte cuando fue constituido como escritor por sus amigos de Port-Royal. Es bien conocido el caso de los Pensamientos, conjunto de fragmentos reunidos por los editores, o el de Las Provinciales, serie de panfletos anónimos o pseudónimos escritos en colaboración con Arnauld y Nicole. Voy a aludir a un texto menos famoso, que ya estudié de manera más precisa (Maingueneau, 2005): las cartas escritas al duque de Roannez y a su hermana.

En el volumen editado por L. Brunschvicg de Pensamientos y opúsculos, publicado por Hachette en 1897, estas cartas figuran bajo el título «Extractos de las cartas a $\mathbf{M}^{\text {lle }}$ de Roannez». Están colocadas en orden cronológico y precedidas por una fecha («septiembre de 1656» para la I, «domingo 24 de septiembre de 1656» para la II, etc.). Tal modo de presentación trata de dar al lector la sensación de que está leyendo la correspondencia auténtica. En cambio, en las Obras completas de Blaise Pascal publicadas a partir de 1904, también en Hachette, por L. Brunschvicg, P. Boutroux y A. Gazier, figuran entre los «opúsculos», al lado del «Discurso sobre la condición de los grandes» o de la «Oración para pedir a Dios el buen uso de las enfermedades». En definitiva, podemos identificar dos estrategias editoriales muy diferentes: una consiste en acercar esas cartas a un supuesto estado original, el de una correspondencia privada ordenada cronológicamente; la otra consiste en borrar tanto como sea posible la dimensión interaccional para subrayar la expresión de una doctrina. En el primer caso, el lector lee algunas cartas que pertenecen a la esfera privada; en el otro, se enfrenta a textos en los cuales un pensador articula su doctrina.

Estas fluctuaciones se explican fácilmente. En efecto, no disponemos del original de esas cartas. Fue sólo hacia 1730 cuando se encontraron extractos en los archivos de la familia Pascal, que estaban ordenados de manera no cronológica. El hecho de que se hayan escogido pasajes fuertemente doctrinales, muestra que se había asociado a Pascal una imagen de autor religioso, de cristiano ejemplar del cual se debían recoger piadosamente las huellas, con fines de edificación. Así pues, es la imagen que se formaba de Pascal lo que decidió el modo en que se debían tratar los textos de géneros tan diversos que había dejado. Esta imagen hizo posible la conversión de los textos en una «obra», la cual permitió a su vez activar nuevas imágenes de autor de Pascal. Más adelante, ya no fue asociado a una imagen de escritor religioso, sino a la de «gran escritor» francés, correlato de una Obra capital. Ya no se suponía que los lectores debieran posicionarse a favor o en contra de las ideas de Pascal, sino recibir este texto como un monumento legado por la Tradición. Sin embargo, casi ninguno de los textos que figuran en las Obras completas fue publicado por alguien que se diera a ver como «auctor».

Los dos modos de construcción de la imagen de autor -en vida del escritor y tras su muerteinteractúan: el primero condiciona al segundo, ya que la obra legada resulta, en buena parte, de las 
elecciones del escritor; pero el segundo condiciona también al primero, ya que se reinterpretan los signos dejados por el escritor. El borrado, el olvido, es una forma radical de este trabajo interpretativo. Permitirá posibles «redescubrimientos» que no tienen nada de desinteresado: directa o indirectamente, se trata, para los que se encargan de ello, de construir la imagen de autor más favorable a su propio posicionamiento.

Un ejemplo canónico de reinterpretación interesada de la imagen de autor sería el de Proust y Nerval. En Contra Sainte-Beuve, Proust reprocha al autor de Los Lunes ${ }^{7}$ haber construido una imagen falsa de Nerval: la de «un escritor anclado en el siglo XVIII y a quien el romanticismo no influenció, un Galo puro, tradicional y local, que dio en Silvia una pintura ingenua y fina de la vida francesa idealizada» (Proust, 1954: 148-149). Según Proust, en cambio, para pensar a su verdadera altura el genio de Nerval, conviene proponer una imagen muy distinta, la de un artista romántico maldito. El recuerdo del patético fin de Nerval, del «subjetivismo» exacerbado de su locura, viene a autentificar así el romanticismo de un escritor paria y el carácter irreductible de su disidencia en relación a cualquier grupo. Esta refundición de la imagen de autor de Nerval permite de hecho a Proust legitimar su propia estética, fundada, como se sabe, sobre la noción de «visión interior»: «en tales genios la visión interior es muy certera, muy poderosa» (Proust, 1954: 150).

La noción de imagen de autor presenta así dos caras muy diferentes, según remita a la gestión de un Thesaurus por parte de participantes exteriores, o a un proceso que se funde con la elaboración de una obra por parte del escritor. Una vez el productor ha accedido a la notoriedad, su «persona» es a menudo absorbida por «el escritor». Esta gestión de la carrera literaria puede realizarse a través de trayectorias muy diversas. Pero algunos productores necesitan mucho más tiempo que otros para conseguirlo. Este «retraso» se puede explicar con razones muy distintas: el productor empieza a escribir tardíamente, escribe pero no consigue que lo publiquen, publica sin acceder a la notoriedad.

\section{Algunas facetas de la imagen de autor}

Lo quiera o no, el escritor construye una imagen de sí a través de una multitud de comportamientos verbales o no verbales mediante los cuales muestra lo que es, para él, ser escritor. Pero su imagen de autor efectiva se elabora, por una parte, en la interacción entre esos comportamientos y las obras; y, por otra parte, en la interacción entre esas obras y las reacciones de los públicos.

Para empezar, consideremos las obras. Debemos tener en cuenta varios factores. En particular:

El tipo de personaje. En el teatro esos personajes son locutores encarnados, lo que facilita la contaminación de la imagen de su autor. Así es como en Francia, Marivaux tuvo durante mucho tiempo una imagen de autor encantador, fútil y precioso $^{8}$, que se asociaba especialmente con las criadas de sus comedias más famosas. Pero esta contaminación también sirve para los personajes de

\footnotetext{
${ }^{7}$ Se le denomina así por los numerosos volúmenes de su obra Causeries du lundi [Las charlas del lunes]. [N. de la T.]

${ }^{8}$ El preciosismo francés se desarrolló en el siglo XVII,vinculado a un uso particular de la lengua, que trata de potenciar su refinamiento retórico. Se gestó en los salones conducidos por mujeres de la alta sociedad parisina, que lograron así descentralizar el saber y el poder de la corte. [N. de la T.]
} 
novela, e incluso para algunos tipos de poesía. Meursault, enfrentado al absurdo en El Extranjero de Albert Camus, o el poeta de los poemarios más famosos de Lamartine que yerra melancólicamente en el campo, contribuyen a perfilar una cierta imagen de su autor. A veces, la identificación del autor con uno de sus personajes es inevitable; es el caso del personaje de Figaro que se considera habitualmente el doble de Beaumarchais. Pero más allá de los personajes, es necesario evidentemente tener en cuenta el «clima» del relato en el cual participan: Meursault está asociado al absurdo únicamente a través de una escenografía narrativa que muestra un universo regido por lo absurdo. Es aquí cuando reencontramos la problemática del ethos discursivo.

El enunciador y la escenografía que implica tienen en efecto un papel esencial, en la medida en que liberan un ethos discursivo. La absurdidad del mundo de El Extranjero es indisociable del ethos de su narrador, tal y como se activa a través de un acto de enunciación cuyo enunciador parece ausentarse. El ethos profético del enunciador hugoliano de la madurez no puede no contaminar la imagen de su autor.

Los géneros tienen también un papel en la construcción de la imagen de autor. La novela de Albert Camus y los poemarios líricos de Lamartine se enuncian con el «yo». Pero el hecho de que $E l$ Extranjero sea una novela y de que el personaje tenga un nombre diferente al del autor hacen que la contaminación entre el personaje y el autor no pueda ser inmediata. Admitimos sin dificultad que Albert Camus ha querido ilustrar una tesis, en este caso la absurdidad de la existencia, pero las representaciones activadas por la lectura de su novela no se trasladan mecánicamente a la persona del autor. Sin embargo, cuando uno lee en un poema de Lamartine versos como estos:

Sigo con paso soñador el sendero solitario;

y adoro volver a ver, por una última vez,

Al sol que palidece, y cuya débil luz

Apenas atraviesa, ante mí, la oscuridad de los bosques. ${ }^{9}$

El solo hecho de que se trate de poesía lírica romántica provoca naturalmente una interferencia entre el actante de la historia, el enunciador del poema y el personaje de Alphonse de Lamartine. Esto no es un accidente, sino una consecuencia a la vez del género (poesía lírica) y de un posicionamiento romántico que concibe la poesía como la expresión inmediata de los efectos del escritor.

El autor-responsable: con este término, me refiero aquí, de manera restrictiva, a la instancia que figura en la portada, la que se presenta como responsable del texto y del paratexto. Su ethos contribuye también a la imagen de autor. Pero en este punto, cabe distinguir:

- El ethos que se desprende de la enunciación del texto propiamente dicho: el autor es percibido por el lector como alguien bien documentado, cultivado, imaginativo, al que le gustan los capítulos cortos, etc. Reencontramos aquí el «autor implícito» de W. Booth.

- El ethos que se desprende del paratexto: el título, pero también los prefacios, prólogos o postfacios, que firma precisamente «el autor». Por ejemplo, en una novela africana titulada $E l$

\footnotetext{
${ }^{9}$ La traducción es de E. Ehrendost.
} 
Círculo de los Trópicos, encontramos en epígrafe estas líneas, firmadas «el autor»; liberan un ethos específico:

La dificultad de escribir esta novela no fue la de construir mi historia, el problema fue, durante meses, el «yo» de Bohi Di... Ser uno de los centenares de millones de hombres anónimos del Tercer Mundo del cual nadie conoce el rostro y que, de repente, murmura, como molesto por molestar el mundo: «No sabéis nada de mí, nada, os lo ruego, escuchad mi historia, la que os voy a contar... Mi nombre es Bohi Di, en mi idioma, eso significa "hijo de la tierra" [...]».

El mismo nombre de autor: el nombre inscrito sobre la tapa es suficiente para activar representaciones que contribuyen a la imagen de autor. Cuando Balzac publicó una novela de juventud bajo el nombre de Lord Rhoone, buscaba estar en harmonía con el género de su texto, inspirado por la novela gótica inglesa, entonces de moda. Hoy en día, los autores de novela sentimental perteneciente a la subliteratura tienden a tomar pseudónimos femeninos con resonancia anglosajona. Si un mismo escritor utiliza varios nombres de autor, van a construirse imágenes distintas: ya conocemos la heteronimia de F. Pessoa o, en Francia, la pareja de pseudónimos Romain Gary/Émile Ajar.

El ethos editorial: este ethos se desatiende a menudo, aunque tiene un papel importante. Es el que se desprende de la colección en la cual se publica el libro, del papel utilizado, de la cubierta. En este mismo orden de ideas, podríamos evocar el director para el teatro, que formatea también el enunciado. Cuando, en el siglo XIX, las novelas de Julio Verne eran publicadas en la colección «Voyages extraordinaires» y destinadas a la educación de los niños, la imagen de autor del escritor era muy diferente de la que prevalece hoy.

Por su parte, el escritor, en tanto actor de la institución literaria, a través de sus comportamientos y de sus textos de acompañamiento («el espacio asociado» descrito en nuestro Discours littéraire) se esfuerza por controlar su imagen de autor, que gestiona en función de la percepción que tiene de ella. Reencontramos aquí también la distinción, a la vez necesaria e imposible, entre «escritor»y «persona».

- El escritor: actor en la escena literaria, produce signos a través de sus textos de «figuración» y sus textos de «configuración» [réglage], pero también a través de algunos gestos significantes: así, las provocaciones de los surrealistas, la batalla de Hernani para los románticos, etc. También atañen al «espacio asociado» del escritor las elecciones editoriales: ser publicado por pequeños editores de vanguardia o por editores reconocidos, publicar su novela en capítulos en un diario de masas o en una revista literaria con tirada muy limitada, etc.

- La persona: sus relaciones con «el escritor», actor de la institución literaria, y el enunciador son muy variables. Ya vimos que, sobre este punto, el Contra Sainte-Beuve de Proust tiene tendencia a autorefutarse: tras haber afirmado que no se debía tener en cuenta la vida del autor para entender su obra, invoca elementos de la vida de Nerval para modificar el sentido de su obra. Sin embargo $-\mathrm{y}$ aquí radica toda la dificultad-, las relaciones entre estas instancias no son estables; varían en función de las épocas y de los posicionamientos literarios. Hoy es imposible abordar a Céline sin saber que colaboró con los alemanes durante la Segunda Guerra Mundial, tanto más cuanto buena parte de su 
obra evoca este periodo de su vida. Si para algunos productores como Céline, Jean-Jacques Rousseau o André Gide, la puesta en escena de su propia vida constituye la trama misma de la obra, otros se obstinan a establecer barreras herméticas entre ellas. Pero la mayor parte de los escritores establecen acuerdos entre estos dos extremos. De manera general, la literatura desde el romanticismo a menudo juega a confundir la frontera entre la vida de la persona, las estrategias del escritor y la obra. En cambio, la imagen de autor a la cual se asocian hoy los escritores del siglo XVI o del siglo XVII tiene poco en cuenta los datos biográficos.

También habría que incluir aquí el conjunto confuso de enunciados que participan activamente de la imagen de autor: rumores, habladurías, indiscreciones... La información según la cual Rousseau habría abandonado a sus hijos al nacer fue proporcionada por el propio Rousseau en un texto que publicó -lo cual no significa que tal información sea verdadera...-. Así pues, no tiene el mismo estatus que un rumor o que algo conocido al hurgar en los papeles del difunto después de su muerte.

Sin embargo, toda distinción entre las zonas de activación de una imagen de autor tiene algo artificial: en cuanto dejamos el círculo de los especialistas, las fuentes tienden a mezclarse; la imagen de autor aparece como una nebulosa inestable, hecha de elementos no jerarquizados extraídos de múltiples fuentes.

\section{Diversidad en el espacio y el tiempo}

Como el autor, la imagen de autor tampoco es un punto fijo ni una zona de contacto entre instancias estables: es una frontera movediza, resultante de un juego de equilibrio inestable en reconfiguración permanente. La noción de imagen de autor, de hecho, como todo lo que atañe a la autorialidad, es particularmente sensible, en efecto, a la diversidad del hecho literario en el espacio y el tiempo. Sabemos que la figura misma del escritor, considerado como la figura clave de un ámbito consistente y autónomo que sería «la literatura», sólo se instaló en la cultura a partir del final del siglo XVIII. Por lo tanto, no podemos tomar como referencia el régimen que se instauró en el fin de siglo XVIII y principios del XIX, aunque domine aún nuestras representaciones.

Por ejemplo, el papel crucial desempeñado por los manifiestos durante los siglos XIX y XX es indisociable de la existencia de un campo literario que se quiere autónomo: cada grupo se constituye ostentosamente en torno a una cierta definición de lo que es la «verdadera» literatura. Lo que concierne al trabajo de «figuración» y de «configuración» conoce entonces un desarrollo sin precedentes: vemos proliferar los textos autobiográficos y los comentarios de los escritores sobre su obra y el Arte. Dado que la competencia entre posicionamientos se exacerba y se teatraliza, y que las definiciones de la actividad literaria son radicalmente inciertas, el productor está abocado a multiplicar los textos que moldearán una imagen de autor que se quiere singular. Ya no estamos en un régimen discursivo en el cual un cierto número de normas se imponen a los escritores, sino en un universo en el cual el escritor debe constantemente legitimar su proceso creativo elaborando una imagen de autor a la medida de su obra. 
Si consideramos los siglos inmediatamente anteriores - por no hablar de la Edad Media o de la Antiguiedad- observamos una multitud de ejemplos en los cuales las categorías que hoy son habituales se revelan poco operativas. En el siglo XVII, por ejemplo, muchos autores no firman prefacios sino «epístolas dedicatorias». Esto va a la par con un cierto estatus del escritor, que necesita el apoyo de protectores ricos. En materia de responsabilidad autorial, el equívoco es entonces la norma. Un gran número de obras de esta época, hoy publicadas bajo nombres propios tranquilizadores, no lo estaban originariamente: la primera edición de La Princesa de Clèves no tiene nombre de autor. De hecho, muchos textos se publican entonces de manera anónima, o con acrónimos más o menos opacos, con pseudónimos o incluso con nombres «falsos». Algunas obras de un autor tan reconocido como Boileau fueron publicadas bajo anonimato y reconocidas más tarde por él mismo, a veces mucho tiempo después.

En efecto, publicar un texto en el sigo XVII no significa necesariamente firmarlo, atribuirle un autor. Aquí intervienen varios factores, vinculados en particular al control real sobre los impresores, o a representaciones sobre el carácter muchas veces degradante que tendría, para una persona de calidad, el hecho de reconocerse escritor. Todo ocurre como si presentarse como autor fuera un riesgo. Además, muchos de los que publican una obra no se presentan como personajes públicos que toman la responsabilidad de un texto. De ahí la importancia del espacio del peritexto (dedicatoria, discours d'escorte ${ }^{10}$, autógrafos y alógrafos...), en el cual uno se esfuerza por gestionar la incertidumbre en cuanto a la identidad del autor.

Esas múltiples publicaciones que juegan con el secreto, la elusión, suscitan una imagen de autor confusa, incierta, con la cual juegan los escritores. Se trata aquí de un juego sutil en el cual un cierto número de personas conocen la identidad del productor, que, sin embargo, o bien no se reconoce públicamente como tal, o bien lo hace más tarde. Aquí la noción de «enmascaramiento» parece reductora. No obstante, es difícil evaluar hasta qué punto, y para qué público, la identidad social del autor anónimo o enmascarado era «de notoriedad pública», intuida, o permanecía indescifrable; hasta qué punto no firmar equivalía a firmar de otro modo.

Además, en muchos textos, el que reivindica todo o parte del peritexto multiplica ostensiblemente las indicaciones equívocas: «yo» soy $v s$ «yo» no soy el autor de este texto. Es el caso, por ejemplo, de Charles Sorel.

Conocemos la complejidad de la «firma» del Francion. En el primer Recueil de pièces en prose les plus agréables de ce temps, Sorel insiste sobre el hecho que reunió «Piezas diferentes en cuanto al tema y al estilo, como lo son las que vienen de diferentes Autores» (París, Charles de Sercy, 1650, «A los lectores»). Sin embargo, a pesar de la diversidad efectiva, reconocemos en realidad modulaciones de su estilo, como si él mismo fuera varios, y evoca de hecho en La Biblioteca francesa, sin avalarla del todo, la opinión según la cual él es esencialmente el autor. Y nada más

\footnotetext{
${ }^{10}$ Discours d'escorte: literalmente discurso de escolta. En el teatro hace referencia a un apóstrofe en el cual el autor dramático se dirige directamente al lector, para abrir reflexiones metaliterarias a propósito de su obra, las posibles objeciones que puede recibir, su significado, etc. [N. de la T.]
} 
complejo que este Ordre et [...] examen des livres attribuez à l'autheur de la Bibliothèque françoise («M. C. Sorel» según la página del título). «Él» (el rechazo al «yo» es perceptible) empieza por una reivindicación de libertad: los autores deben ser de condición libre; por consiguiente, tienen derecho a escoger lo que consideran poder elevar «al rango de sus verdaderas Obras»: «Nunca existió la obligación de decirse el Autor de Libros que desaprobamos al darlos, y que sólo damos como Libros Ajenos, sentimientos y método con los cuales no estamos de acuerdo» (citado en Nédelec, 2004: 14).

Al evocar así el siglo XVIII, en el cual domina el impreso, no nos hemos alejado considerablemente del mundo que nos es familiar. La actividad de producción de un texto propiamente dicha no es en el fondo diferente entre el siglo XVII y el siglo XX. Pero las cosas se complican especialmente si pensamos en sociedades que mezclan oralidad y escritura, como la Edad Media, por ejemplo. Contrariamente a lo que da a entender M. Foucault, esta época no se contenta con oponer los grandes autores de la Antigüedad a voces anónimas que publican en lengua vernácula (Thiry et alii 2005, Doudet 2008). De hecho, el problema varía en función de los momentos y géneros literarios: la canción de gesta coloca al recitador en primer plano, mientras que la novela, que en Francia se difunde a mitad del siglo XII, tiene un vínculo mucho más fuerte con la escritura y empieza a manifestar una competencia entre los autores antiguos y los autores contemporáneos. De todas maneras, el léxico no propone indicadores estables, ni para el significante ni para el significado, que sean susceptibles de referir un estatus de productor de textos. A los términos muy imprecisos de «clérigo»o «poeta», se añaden múltiples perífrasis («el que noveliza» [celui qui met en roman], «el que cuenta» [celui qui conte], «el que rima» [celui qui met en rime], «el que versifica» [celui qui met en vers]...), de las cuales es muy difícil decir qué abarcan exactamente. ¿Y qué decir de la «firma», de la mención del nombre de autor, que a menudo está integrada en el interior mismo del texto?

Fenómenos tan masivos no pueden ser remitidos a la psicología individual: definen regímenes de autorialidad que complejizan considerablemente lo que podemos entender por «imagen de autor».

\section{Conclusión}

Un enfoque del discurso literario que pretenda librarse de la categoría de imagen de autor se expone a tener de ella una concepción reductora. Los tres polos de la comunicación están concernidos por esta problemática:

- El polo de la producción, ya que el creador ajusta su producción en función de la imagen que no deja de construirse mediante el conjunto de su actividad, escritural [scripturaire] o no.

- El polo del texto, ya que el formato [formatage] e incluso la organización [découpage] y la puesta en circulación de los textos dependen de la imagen de autor: en un tipo de discurso como la literatura, en el cual la inmensa mayoría de textos pertenecen a un Thesaurus pasado, hay aquí una dimensión esencial.

- El polo de la recepción, ya que la decisión para un individuo de entrar en un proceso de comunicación con un texto (leerlo, ir al teatro...) depende de la imagen de autor, que condiciona 
además el conjunto de las estrategias de interpretación. Cuando el «salvaje» de Brave New World de Aldous Huxley lee las obras de Shakespeare sin saber quién es Shakespeare y en qué época vivía, no se puede decir que lee textos de Shakespeare.

Pero esta noción de imagen de autor es particularmente delicada a la hora de manejarla, porque las categorías de las cuales disponemos habitualmente no están hechas a la medida de tales fenómenos: privilegian entidades (ilusoriamente) estables, «el hombre» o «la obra», en detrimento de interacciones entre entidades heterogéneas.

Es claramente más confortable adoptar la conducta de erudito, enumerando las singularidades de un escritor, un género, una época... De hecho, la abundancia y la complejidad de los materiales es impresionante si se quieren inventariar todos los problemas que plantea la construcción de la imagen de autor, teniendo en cuenta las múltiples formas de anonimato o pseudoanonimato, los autores inventados o construidos, colectivos o singulares, etc. Este tipo de investigación está favorecida por el hecho de que los estudios literarios están subdivididos, en general, por autores o por periodos. El problema es que, si bien la erudición es indispensable, no tiene fuerza explicativa. Las descripciones de singularidades no pueden sustituir a un análisis de las condiciones de funcionamiento de la actividad literaria.

Me parece que podemos encontrar un marco de investigación más adaptado en el análisis del discurso, que puede apoyarse en el enorme saber que se ha acumulado a lo largo de los siglos sobre los autores, las obras y los mundos de los cuales participan. Buscando articular invariables sobre la diversidad de situaciones, recusando las formas tradicionales de exterioridad del texto y del contexto, reflexionando en términos de movimiento e interacción, este tipo de enfoque está a priori mejor armado para aprehender cuestiones como la de imagen de autor. No me cabe la menor duda de que comienza aquí una inmensa tarea.

\section{Referencias bibliográficas}

Booth, Wayne (1961): The Rhetoric of Fiction. Chicago, University of Chicago Press.

Doudet, Estelle (2008): «Par le nom conuist an l'ome. Désignations et signatures de l'auteur, du $\mathrm{XII}^{\mathrm{e}}$ au XVI $\mathrm{XI}^{\mathrm{e}}$ siècles», en P. CHIRON y F. Claudon, eds., Constitution du champ littéraire. Limites, intersections, déplacements. París, L’Harmattan, pp. 105-124.

Foucault, Michel (1969a): «Qu'est ce qu'un auteur?», Bulletin de la Société française de philosophie, 63/3, pp. 73-104. Reimpreso en Dits et écrits I, 1954-1975. París, Gallimard, 1994, pp. 817-849.

— (1969b): L’Archéologie du savoir. París, Gallimard. [La arqueología del saber. Trad. de Aurelio Garzón del Camino. Buenos Aires, Siglo XXI, 2002.]

Maingueneau, Dominique (2004): Le Discours littéraire. Paratopie et scène d'énonciation. París, Armand Collin.

- (2005): «Détachement et surdestinataire. La correspondance entre Pascal et les Roannez», Semen, 20, pp. 83-96. 
30 Tropelías. Revista de Teoría de la Literatura y Literatura Comparada, 24 (2015)

Dominique Maingueneau

- (2006): Contre Sainte Proust. París, Belin.

(2009): «Auteur et image d'auteur en analyse du discours», Argumentation et Analyse du Discours, 3, en línia.

MeIzOZ, Jerôme (2007): Postures littéraires. Mises en scène modernes de l'auteur. Genève, Slatkine.

NeDELEC, Claudine (2004): «Équivoques de l'auctorialité au XVIIe siècle», Les Cahiers du Centre de Recherches Historiques, 33, pp. 27-40.

Proust, Marcel (1954): Contre Sainte-Beuve. París, Gallimard, 1987.

SOREL, Charles (1667): La Bibliothèque française. Genève, Slatkine, 1968.

Thiry, Claude, Minet-Mahy Virginie y VAn HeMELRYCK Tania, eds. (2005): Fonctions et figures d'auteurs du Moyen-Âge à l'époque contemporaine. Número especial fuera de serie de Les Lettres romanes. 